\title{
Sequence analysis demonstrates the conservation of fim $H$ and variability of fimA throughout Avian Pathogenic Escherichia coli (APEC)
}

\author{
Fréderic VANDEMAELE ${ }^{\mathrm{a} *}$, Dominique VANDEKERCHOVE ${ }^{\mathrm{b}}$, \\ Monita VEREECKEN ${ }^{\mathrm{c}}$, Jef DERIJCKE ${ }^{\mathrm{c}}$, Maryvonne DHO-MOULIN ${ }^{\mathrm{d}}$, \\ Bruno Maria GODDEERIS ${ }^{\mathrm{a}, \mathrm{e}}$
}

\author{
${ }^{\text {a }}$ Laboratory of Physiology and Immunology of Domestic Animals, \\ Catholic University Leuven, Kasteelpark Arenberg 30, 3001 Leuven, Belgium \\ ${ }^{\mathrm{b}}$ Small Stock Diseases, Veterinary and Agrochemical Research Centre (VAR), Groeselenberg 99, \\ 1180 Brussels, Belgium \\ ${ }^{c}$ Animal Health Care, East Flanders, Deinse Horsweg 1, 9031 Drongen, Belgium \\ ${ }^{\mathrm{d}}$ Institut National de la Recherche Agronomique, Station de Pathologie Aviaire et de Parasitologie, \\ Centre de Recherches de Tours, 37380, Nouzilly, France \\ ${ }^{\mathrm{e}}$ Department Virology, Parasitology and Immunology, Faculty Veterinary Medicine, \\ University Ghent, Salisburylaan 133, 9820, Merelbeke, Belgium
}

(Received 27 May 2002; accepted 30 September 2002)

\begin{abstract}
In this study we sequenced and analysed the fimH and fimA genes of 24 avian pathogenic Escherichia coli (APEC) isolates, in order to investigate their possible conserved nature. Additional parameters (serotype, presence of aerobactin receptor, expression of F1 pili and virulence for chickens) were investigated to look for correlations with the obtained sequences. The sequence analysis demonstrated that FimH is highly conserved among all investigated APEC strains (> 99\% homology), whereas the major subunit FimA is less conserved, presenting 6 variable regions distributed along the protein. A hydrophilicity analysis suggested several variable domains of FimA to be potential epitopes. We were able to classify the investigated strains into three main groups, on the basis of the amino-acid sequences of the variable regions. This grouping was consistent throughout all variable regions and was independent of serotype, leading to an improved classification of the F1 pili. No correlation was found between the fimH and fimA sequences and the following parameters: avian species, organ of isolation, serotype, presence of aerobactin receptor and virulence for chickens. This study elucidated the molecular structure and the degree of conservation of FimH and FimA among various avian pathogenic E. coli strains.
\end{abstract}

\section{Escherichia coli / avian / APEC / FimH / FimA}

\section{INTRODUCTION}

Escherichia coli infections are often diagnosed in animals and humans. In humans, pathogenic E. coli are responsible for both intestinal (diarrhoea) and extraintestinal (urinary tract infection, meningitis) diseases, while in avian species $E$. coli

\footnotetext{
* Correspondence and reprints

Tel.: (32) 163214 33; fax: (32) 1632 19 94; e-mail: Frederic.vandemaele@agr.kuleuven.ac.be
} 
infection only results in extra-intestinal diseases. Avian colibacillosis is initiated by an infection of the upper respiratory tract and often leads to a general infection of the internal organs: pericarditis, perihepatitis, peritonitis and salpingitis. This often results in loss of egg laying and death, causing substantial economic losses $[4,8]$.

An important step in the infection process is the adherence of APEC to the epithelium of the trachea. This could allow the bacteria to overcome resident defence mechanisms (tracheal mucus layer) and to perform a more successful colonisation. This adhesion phenomenon is mediated by the F1 pili, which are proteinaceous structures present on the outer membrane of most strains of $E$. coli and of several other members of the Enterobacteriaceae [8, 17]. The $\mathrm{P}$ pilus could also play an important role in avian colibacillosis. It is thought to act only in the later stages of the infection (internal organs), since $\mathrm{P}$ pili are not expressed in vivo on bacteria colonising the tracheal epithelium [17].

The fim gene cluster, which encodes the F1 pilus, consists of nine genes, seven of which are organised in a single operon [10]. The F1 pilus is composed of a major protein subunit, FimA (about 1000 subunits per pilus) and of several minor subunits, FimF, FimG and FimH [11]. The minor subunit FimH is comprised of 279 amino acids in its mature form and mediates adhesion to D-mannose residues, which are present on the tracheal epithelial cells, macrophages and many other host cells $[9,17]$.

The tracheal adhesion mediated by F1 pili has been proposed to play a role in the virulence of APEC [7, 18]. However, a debate still remains on the exact role of the F1 pilus and its FimH adhesin. A study by Marc et al. and Arné et al. [1, 12] demonstrated that neither the $\mathrm{F} 1$ pili nor FimH are strictly required for a successful colonisation of the respiratory tract in poultry, suggesting a more limited role in pathogenicity. However, FimH has been proven essential to human urinary tract infection, since deletion of FimH abolishes infection [14]. The FimH adhesin has been described to be conserved throughout several strains of $E$. coli and even other F1 fimbriated Enterobacteriaceae [2]. Several important amino acids in the protein have been identified and extensively analysed $[16,20,21]$. On the contrary, the FimA major protein has been reported to be variable between the different strains of E. coli [2].

The aim of this study was to elucidate the degree of conservation or variability of FimH and FimA in APEC strains, in order to allow construction and testing of an F1-based subunit vaccine. Although a vaccine currently exists against the F11 serotype of the $\mathrm{P}$ pilus (marketed by Intervet International, Boxmeer, The Netherlands), it will be interesting to investigate whether an F1-based subunit vaccine can offer a broader protection. An essential condition for the development of a broad range vaccine is the conserved nature of the antigen (i.e. FimH or FimA), which was analysed in this study. Moreover, a number of additional characteristics were determined (serotype, presence of an aerobactin receptor, expression of type 1 pili and virulence) to detect the possible correlations with FimH and FimA sequences.

\section{MATERIALS AND METHODS}

\subsection{Bacterial strains and media}

All E. coli strains from Belgium were isolated from animals showing distinct clinical symptoms of APEC infection (pericarditis, perihepatitis, peritonitis, salpingitis) and were collected on poultry farms from different parts of the country (Tab. I). The reference strains (MT203, MT512 and EC79) were extensively characterised and used in numerous studies [57, 13]. MT203 and MT512 were proven virulent in in vivo virulence studies. EC79 
Table I. Analysed APEC strains.

\begin{tabular}{|c|c|c|c|c|c|c|c|c|}
\hline $\begin{array}{l}\text { APEC } \\
N^{\circ}(1)\end{array}$ & $\begin{array}{l}\text { Date of } \\
\text { collect }\end{array}$ & Place & Type of animal & Organ & $\begin{array}{l}\text { Alive } \\
(2)\end{array}$ & $\begin{array}{c}\text { Serotype } \\
\text { (3) }\end{array}$ & $\begin{array}{c}\text { FimH } \\
\text { accession } \\
\mathrm{N}^{\circ}(4)\end{array}$ & $\begin{array}{c}\text { FimA } \\
\text { accession } \\
\mathrm{N}^{\circ}(4)\end{array}$ \\
\hline 125 & $01 / 01$ & Belgium & Laying hen breeder & Peritoneum & No & NT & AF490846 & AF490870 \\
\hline MT512 & $04 / 72$ & France & Laying hen & Trachea & Yes & $\mathrm{O} 2$ & AF490867 & AF490889 \\
\hline 21 & 06/00 & Belgium & Broiler chick & Pericard & No & $\mathrm{O} 2$ & AF490854 & AF490877 \\
\hline 115 & 01/01 & Belgium & Laying hen breeder & Pericard & No & $\mathrm{O} 1$ & AF490844 & AF490868 \\
\hline 128 & $01 / 01$ & Belgium & Laying hen breeder & Pericard & No & NT & AF490847 & AF490871 \\
\hline 58 & $09 / 00$ & Belgium & Broiler chick & Pericard & No & O115 & AF490859 & AF490882 \\
\hline 6 & $10 / 00$ & Belgium & Broiler chick & Pericard & No & NT & AF490862 & AF490885 \\
\hline 13 & $04 / 00$ & Belgium & Broiler chick & Pericard & No & NT & AF490850 & AF490874 \\
\hline 54 & $09 / 00$ & Belgium & Peacock chick & Pericard & No & $\mathrm{O} 2$ & AF490856 & AF490879 \\
\hline 121 & $01 / 01$ & Belgium & Laying hen & Pericard & Yes & NT & AF490845 & AF490869 \\
\hline 60 & 09/00 & Belgium & Laying hen & Pericard & No & $\mathrm{O} 78$ & AF490861 & AF490884 \\
\hline 7 & $10 / 00$ & Belgium & Laying hen & Pericard & No & $\mathrm{O} 78$ & AF490863 & AF490886 \\
\hline 5 & $10 / 00$ & Belgium & Broiler chick & Pericard & No & $\mathrm{O} 78$ & AF490860 & AF490883 \\
\hline 57 & $09 / 00$ & Belgium & Laying hen & Peritoneum & No & $\mathrm{O} 78$ & AF490858 & AF490881 \\
\hline 16 & $04 / 00$ & Belgium & Laying hen & Pericard & No & $\mathrm{O} 78$ & AF490852 & AF490876 \\
\hline 15 & $04 / 00$ & Belgium & Broiler chick & Pericard & No & $\mathrm{O} 1$ & AF490851 & AF490875 \\
\hline 133 & $01 / 01$ & Belgium & Laying hen & Pericard & No & NT & AF490848 & AF490872 \\
\hline 56 & $09 / 00$ & Belgium & Laying hen & Peritoneum & No & NT & AF490857 & AF490880 \\
\hline 53 & $09 / 00$ & Belgium & Laying hen breeder & Pericard & No & $\mathrm{O} 78$ & AF490855 & AF490878 \\
\hline 137 & $01 / 01$ & Belgium & Laying hen breeder & Pericard & No & O83 & AF490849 & AF490873 \\
\hline MT203 & $04 / 82$ & France & Turkey chick & Liver & Yes & $\mathrm{O} 1$ & AF490866 & AF490888 \\
\hline 17 & $04 / 00$ & Belgium & Laying hen & Peritoneum & No & NT & AF490853 & NA \\
\hline EC79 & $09 / 75$ & France & Broiler chicken & Feces & Yes & $\mathrm{O} 2$ & AF490864 & NA \\
\hline
\end{tabular}

(1) The strains are ordered according to Figure 1. (2) Alive means that the strain was isolated from an animal, still alive when handed to the laboratory (Animal Health Care, Flanders, Drongen). (3) NT: Non-Typable (serotype not belonging to the 28 serotypes tested). (4) GenBank accession numbers: NA means Not Applicable (no fimA was present).

is a non-virulent reference strain [7] (isolated from the faeces of a healthy chicken). For in vivo virulence tests, two additional strains were tested: an E. coli strain isolated from a pig and the TUNER strain (Novagen Inc., Madison, USA, laboratory strain for expression of proteins). The
Struis strain was isolated from infected ostrich eggs (only the FimA sequence was determined, GenBank accession number AF490890). All strains were stored in a Luria-Bertani (LB) medium containing $15 \%$ glycerol at $-80{ }^{\circ} \mathrm{C}$ and grown in a standard LB medium at $37{ }^{\circ} \mathrm{C}$. 


\subsection{Serotyping and haemagglutination assay}

The bacterial strains were isolated from affected organs. A swab was taken and transferred onto blood agar plates (Columbia sheep blood) and Mac Conkey agar plates. One single colony was selected for further characterisation and sequencing. The strains were classified as E. coli by biotyping (TSI, indole, citrate) and subsequently serotyped (Tab. I), using 28 antisera, specific for the 27 world-wide most frequently occurring APEC serotypes and the zoonotically important O157-serotype (antisera purchased at Sanofi, Pasteur, Chaska, USA). The investigated serotypes were $\mathrm{O} 1, \mathrm{O} 2$, O5, O6, O8, O9, O11, O12, O14, O15, O17, O18, O20, O35, O36, O45, O53, O78, O81, O83, O88, O102, O103, O115, O116, O132 (antisera purchased at the E. coli reference centre, University of Santiago de Compostela, Spain) and $\mathrm{O} 109$ (antisera produced by the VAR, department of Small Stock Diseases).

To investigate the F1 pili expression, an agglutination assay was performed as previously described [7] using blood collected from commercial laying hens and $E$. coli strains grown in Tryptic Soy Broth (TSB) at $37^{\circ} \mathrm{C}$.

\subsection{PCR assays}

Two PCR assays were performed for each strain to amplify the full-length fimH gene $(903 \mathrm{bp})$ and part of the fimA gene (549-555 bp). Preparations of $100 \mathrm{ng}$ of genomic DNA [3] were used as templates in $50 \mu \mathrm{L}$ PCR mixtures containing $4 \mu \mathrm{L}$ dNTP $(2.5 \mathrm{mM}$ each dNTP), $1.25 \mu \mathrm{L}$ of forward and reverse primers ( $20 \mu \mathrm{M}$ each), $2.5 \mu \mathrm{L}$ DMSO, $34 \mu \mathrm{L}$ Dnase free water, $5 \mu \mathrm{L}$ buffer $10 \times$ (Stratagene) and $1 \mu \mathrm{L} P f u$ polymerase $(2.5 \mathrm{U} / \mu \mathrm{L}$, Stratagene, La Jolla, USA). The PCR reaction conditions were as follows: $95^{\circ} \mathrm{C}$ for $2 \mathrm{~min}$, then during 30 cycles: $95^{\circ} \mathrm{C}$ for $30 \mathrm{~s}, 57^{\circ} \mathrm{C}$ for $30 \mathrm{~s}$ and $72{ }^{\circ} \mathrm{C}$ for $2 \mathrm{~min}$, followed by a final elongation $72{ }^{\circ} \mathrm{C}$ for $5 \mathrm{~min}$. The following primers were used for the fimH gene: FimHF: 5' ATGAAACGAGTTATTACCCTGTTTG 3' and FimHR: 5' TTATTGATAAACAAAAGTCACGCC 3'.

For the fimA gene, the primers located in the constant intergenic regions flanking the fimA gene, as described by Peek et al. [15], were used:

97FimAF (forward primer, starts at position -97 , relative to the start codon):

\section{5' ACTGTGCAGTGTTGGCAG 3';}

63FimAR (reverse primer, starts at position +63 relative to the stop codon):

\section{5' GTTATTTTTATCGCACAAGG 3'.}

The PCR products were subsequently purified using the Qiagen PCR Purification Kit and concentrated using a standard ethanol-Na-acetate precipitation.

\subsection{Sequencing and DNA analysis}

Sequencing reactions were performed on the fimH and fimA PCR products using the ABI PRISM Bigdye ${ }^{\mathrm{TM}}$ Terminator Cycle Sequencing Ready Reaction Kit (ABI, Foster City, USA), following the manufacturers manual. After the cycle sequencing reaction, the mixtures were purified and concentrated by ethanol/NaAcetate precipitation. The pellet was redissolved in $2 \mu \mathrm{L}$ red loading buffer (Microstop, Microzone LTD, Lewes, UK). The products were sequenced on a $377 \mathrm{ABI}-$ PRISM automated DNA sequencer according to the manufacturers manual.

The fimH was sequenced using the FimHF and FimHR amplification primers as well as two internal primers: FimHF$_{2}$ and FimHR 2 .

FimHF $F_{2}: 5$, TTGCCGTGCTTATTTTGCGAC 3' (439-459).

FimHR $_{2}$ : 5 CAGCTTTAATCGCCACCCCGC 3' (409-429).

The fimA was sequenced using the $97 \mathrm{AF}$ and 63 AR amplification primers. Due to the limited length of fimA (549 to $555 \mathrm{bp}$ ), no internal primers were needed. The chromatograms of the sequences were 
visualised using the CHROMAS 2.0 software (Technelysium Ltd., Helensvale, Australia). The DNA sequences were analysed (aligned) using DNAMAN version 5.0 (Lynnon Biosoft, Quebec, Canada).

\subsection{Presence of the aerobactin receptor gene}

A PCR assay was performed to detect the iutA gene (encoding the aerobactin receptor) using the following primers:

IutAF: 5'ATGAGCATATCTCCGGACG3', IutAR: 5'CAGGTCGAAGAACATCTGG 3'.

$1.5 \mu \mathrm{L}$ of $E$. coli overnight cultures were used as templates in $20 \mu \mathrm{L}$ PCR mixtures containing $2 \mu \mathrm{L}$ buffer $10 \times, 1.6 \mu \mathrm{L}$ dNTP $(2.5 \mathrm{mM}), 1 \mu \mathrm{L}$ of forward and reverse primers $(20 \mu \mathrm{M}), 1.2 \mu \mathrm{L} \mathrm{MgCl}_{2}(1.5 \mathrm{mM})$, $12.12 \mu \mathrm{L}$ Dnase free water and $0.08 \mu \mathrm{L} \mathrm{Taq}$ DNA polymerase $(2.5 \mathrm{U} / \mu \mathrm{L}$, Promega, Madison, USA). The following PCR conditions were used: $93{ }^{\circ} \mathrm{C}$ for $10 \mathrm{~min}$, followed by 30 cycles: $93{ }^{\circ} \mathrm{C}$ for $1 \mathrm{~min}$, $55{ }^{\circ} \mathrm{C}$ for $1 \mathrm{~min}, 72^{\circ} \mathrm{C}$ for $1 \mathrm{~min}$, concluded by a final elongation of $72{ }^{\circ} \mathrm{C}$ for $5 \mathrm{~min}$.

\subsection{Testing for in vivo virulence}

All 23 strains (20 strains from Belgium and the 3 reference strains from France) were tested for virulence. Each APEC strain was cultured for two periods of $24 \mathrm{~h}$ each in TSB at $37^{\circ} \mathrm{C}$ and $0.5 \mathrm{~mL}$ of the last culture was injected subcutaneously in the necks of five 1-day-old Specific Pathogen Free (SPF) chicks (Lohmann, Cuxhaven, Germany). Mortality was monitored for 5 days. As described in Dho and Lafont [6], if more than 1 out of the 5 chicks died during the 5-day-period, the strain was considered virulent. If no chicks died, the strain was considered non-virulent. Control groups received $0.5 \mathrm{~mL}$ of sterile TSB medium. All experiments on animals were approved by the Ethical Commission for Experimental Use of Animals of the Catholic University Leuven (project number 01059).

\section{RESULTS}

\subsection{Analysis of the FimH protein sequences}

The protein sequences, deduced from the obtained nucleotide sequences, gave a homology $\geq 99 \%$ between the analysed strains. Analysis of the multiple protein alignment indicated that 17 out of the 24 investigated strains presented the amino-acid $\mathrm{N}^{70}-\mathrm{S}^{78}$ motif, 3 presented the $\mathrm{S}^{70}-\mathrm{N}^{78}$ motif and 4 the $\mathrm{N}^{70}-\mathrm{N}^{78}$ motif.

A multiple alignment was performed between the FimH sequences from avian E. coli strains and available FimH sequences from human $E$. coli strains (GenBank accession numbers AF288194 and AF317710). The FimH sequences from the human strains were identical to FimH from the APEC 15, 121 and MT512 strains and a large homology with the other strains was found. Both FimH sequences from human strains presented the $\mathrm{S}^{70}-\mathrm{N}^{78}$ motif. Sequence AF317710 presented an alanine at position 62 (of the mature protein), while all other sequences had a serine. No association of the FimH sequence was observed with the avian species of origin, organ of isolation, serotype, presence of the aerobactin receptor nor with virulence for chicks.

\subsection{Analysis of the FimA protein sequences}

The protein sequences, deduced from the obtained nucleotide sequences, are shown in Figures 1 and 2. No fimA gene was detected in the APEC 17 and EC79 strains, although the fimH gene was present, indicating an incomplete fim operon. Both strains were unable to agglutinate chicken erythrocytes, which was in accordance with their lack of fimA.

Based on the multiple protein alignment (Fig. 2), six variable regions were detected in the FimA sequences: V1 (AA 24-27), 


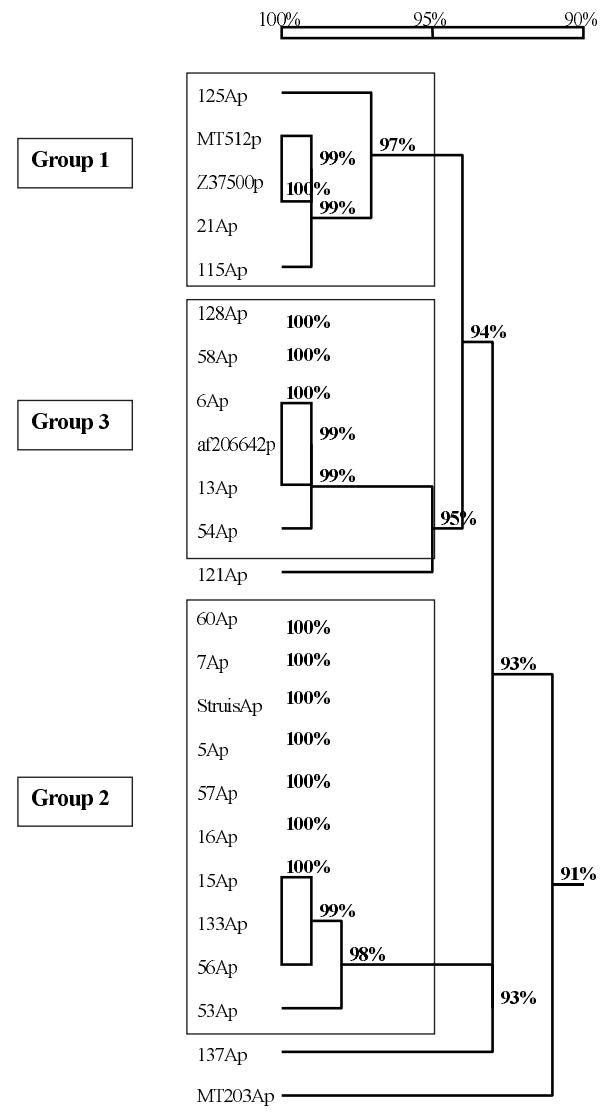

Figure 1. Homology tree of the multiple FimA alignment at the protein level. The three groups (based on the variable domains) are indicated. The percentages indicate the degree of homology. $p$ or Ap indicate that the sequence is a protein sequence.

V2 (AA 65-69), V3 (AA 89-92), V4 (AA 104-109), V5 (AA 134-137) and V6 (AA 145-146). The first variable domain (V1) is characterised by an insertion of two amino acids. Based on the sequences of all variable regions, the analysed APEC strains could be associated in 3 major groups, as indicated in Figures 1 and 2, each presenting a unique consensus sequence. This grouping is consistent throughout the six variable regions. The last two variable regions (V5 and V6) are identical for groups 2 and 3, which can only be distinguished by the other variable regions. Region AA 163-167 could be considered as a seventh variable domain. The motif of this region, as shown in the APEC 125 strain (Fig. 2), is however only present in the APEC 121 and APEC 137 strains and not in the other strains. The latest two strains do not fall entirely in the proposed grouping, as shown in Figure 1. At position 19, there is an additional variable position $(\mathrm{A} \leftrightarrow \mathrm{T})$, which is, however, independent of the proposed grouping.

Group 1 includes the APEC 21, 115, 125 and MT512 strains, group 2 includes the APEC 6, 13, 54, 58 and 128 strains, and group 3 includes the APEC 5, 7, 15, 16, 53, 56, 57, 60, 133 and StruisA (isolated from ostrich) strains. Strain 137 could not be grouped precisely. It is closely related to group 2, but shows a number of additional variations. In the same manner, strain 121 is related to group 3. The homology of the groups was in the range of $92-94 \%$, which is lower than the overall homology in FimH (98-100\%).

Two additional strains, whose fimA sequences had already been determined, were compared to the sequenced strains of this study: strain MT78 is an APEC strain (GenBank accession number Z37500) and strain AF206642 (GenBank accession number) is from mammalian origin. The APEC MT78 strain could be classified in group 1, while the AF206642 strain of mammalian origin belonged to group 3 . When additional sequences of mammalian origin [15] were incorporated into the multiple alignment, all of them fell within the proposed groups and the established variable domains (data not shown).

We studied the hydrophilic or hydrophobic nature of the variable regions of FimA in order to look for potential epitopes (Fig. 3). Region V1 (AA 24-27) was shown to be hydrophobic, while regions V2 (AA 65-69) and V3 (AA 8992) were strictly hydrophilic among all strains and this could indicate possible epitopes. Region V4 (AA 104-109) was 


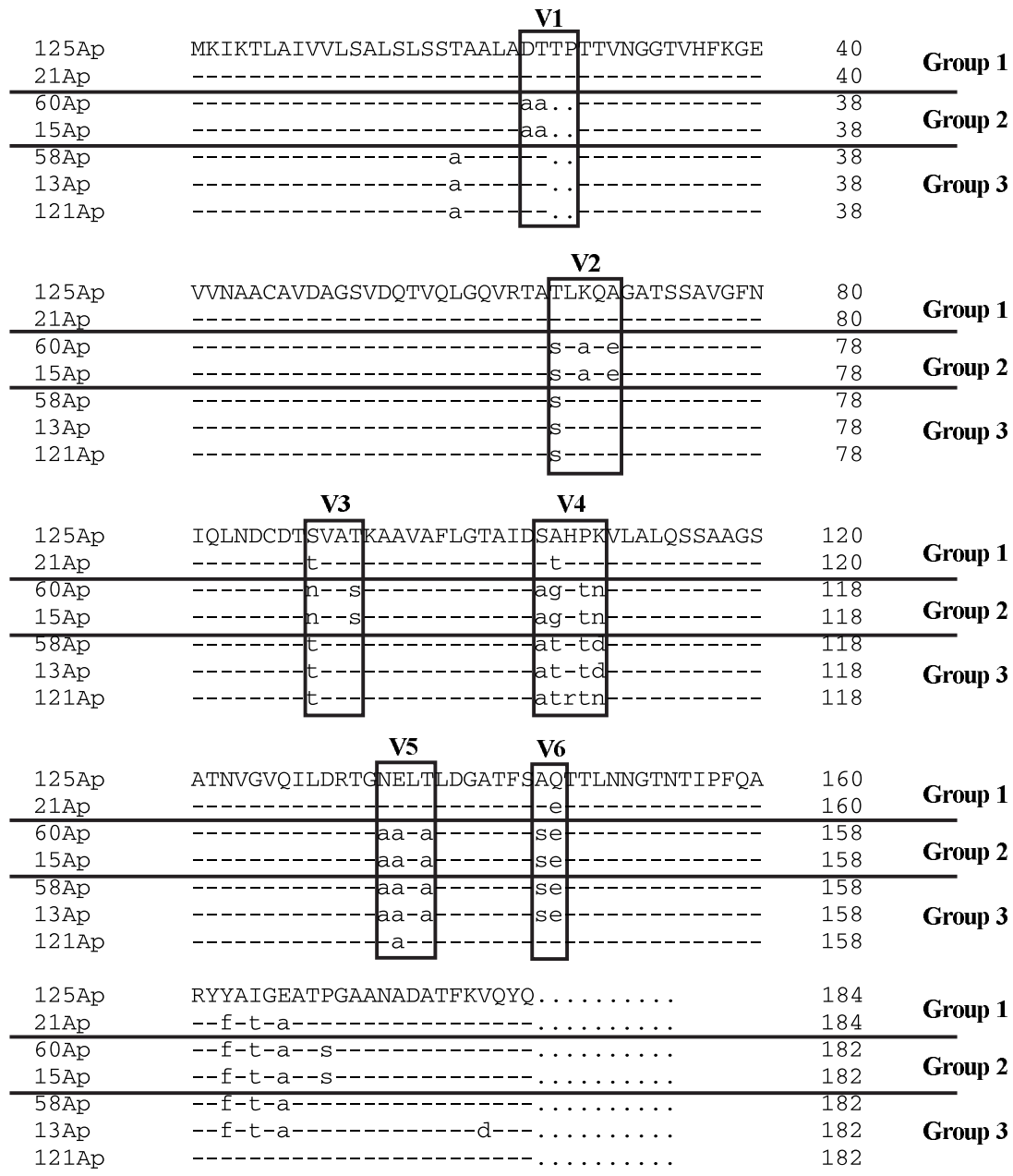

Figure 2. Multiple protein alignment of the FimA sequences. The three groups are indicated and separated by horizontal lines. From each group two or three sequences have been selected to represent the entire group (to limit the alignment). The variable domains are indicated by the black rectangles (V1 to V6).

shown to be partially hydrophilic and partially hydrophobic. Region V5 (AA 134137) was hydrophobic, except in the APEC 125 and APEC 21 strains (see also Fig. 2). Region V6 (AA 145-146) was shown to be hydrophilic for all strains, except for the APEC 121 and APEC 125 strains (AQ instead of SE).
The studied characteristics of the strains (serotype, avian species of origin, organ of isolation, presence of the aerobactin receptor, and virulence for chicks) did not show any association with the grouping of the strains based on the FimA sequence. The serotypes were randomly distributed over the three groups (Tab. I). 


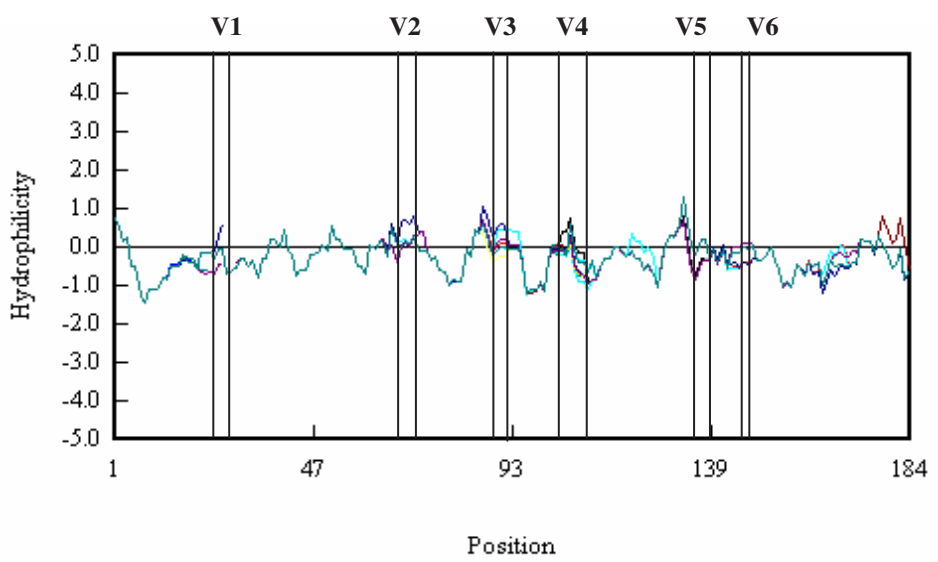

Figure 3. Hydrophilicity plot of FimA. The different curves indicate the different APEC strains. The vertical lines delineate the variable domains, as labelled on top by V1 to V6.

\subsection{In vivo virulence}

All strains from Belgium were shown to be virulent by the lethality test used. The virulent nature of the MT203 and MT512 strains of French origin was confirmed in this experiment. Strain EC79 has been proven non-virulent. The Tuner strain and the pig-isolated strain were both proven to be non-virulent to chickens.

\subsection{Presence of aerobactin receptor gene and $F 1$ pili}

All strains, except APEC 17 and EC79, possessed the aerobactin receptor gene iutA. All strains except two, showed mannose-sensitive haemagglutination, corresponding to the presence of F1 fimbriae. EC79 and APEC 17 did not show any agglutination, in accordance with their lack of fimA. APEC 133 showed mannose resistant-haemagglutination, which could indicate the presence of $\mathrm{P}$ pili, but impaired the detection of the F1 pili.

\section{DISCUSSION}

The goal of this study was to investigate the molecular variability of fimH and fimA in E. coli from avian species and to look for similarities and differences with the current knowledge. Numerous studies have investigated the molecular structure of the fimH gene. However, these studies focussed mainly on fimH isolated from human E. coli. (uropathogenic E. coli). Notably the work of Sokurenko et al. [2022] gives us in-depth insights on the FimH molecular structure, the implications of several amino acid positions and the differences between FimH from commensal and from uropathogenic strains. However, until now, no detailed study of FimH isolated from avian pathogenic E. coli was performed.

Our data clearly demonstrate that FimH is highly conserved (protein homology $\geq 99 \%$ ). A closer investigation of the amino acid sequence reveals some interesting positions. Sokurenko et al. [20] found two consensus sequences, namely $\mathrm{N}^{70}-\mathrm{S}^{78}$ and $\mathrm{S}^{70}-\mathrm{N}^{78}$, both associated with a low adhesion to D-mannose and reported that these phenotypes are characteristic for commensal E. coli strains. In our study, 20 out of the 24 investigated avian strains presented one of both consensus sequences (17 presented $\mathrm{N}^{70}$ $\mathrm{S}^{78}$ and $3 \mathrm{~S}^{70}-\mathrm{N}^{78}$ ). However, these strains were of extra-intestinal origin and their virulence was checked in the present study. Thus the correlation between these 
consensus sequences and the non-virulent, commensal nature of the strains may thus not be valid in avian $E$. coli. In four strains we found a new motif, $\mathrm{N}^{70}-\mathrm{N}^{78}$. It could be that this motif confers to FimH, an altered specificity to D-mannose. However this hypothesis requires further study.

Pouttu et al. [16] demonstrated that the presence of a serine at position 62 of the mature FimH (instead of alanine) completely abolishes binding of E. coli to collagen. All investigated APEC strains and the human AF288194 strain showed a serine at position 62 that could correspond to a lack of collagen binding. Adhesiveness to collagens is an important factor for the penetration of enteric bacteria through tissue barriers in the bloodstream and subsequently to secondary infection sites [19]. The transition of APEC from the air sacs and lungs to the bloodstream occurs through gas-exchange regions and is, in view of the FimH sequence results, probably not mediated by collagen binding. The observed FimH sequences did not show any association with the avian species from which the strains had been isolated. In the same manner, comparison of the FimH sequence from APEC strains with available FimH sequences of $E$. coli of human origin (Crohn disease, meningitis) revealed a $100 \%$ identity with APEC 15 , 121 and MT512 strains and a homology $\geq 98 \%$ with the other APEC strains (alignment not shown), confirming that FimH is not specific.

We also investigated some validation criteria for the characterisation of APEC strains (virulence, presence of the aerobactin receptor, presence of F1 pili). No association was found between these criteria and the FimH sequence. Moreover, there appears to be no association between the FimH sequence and the following parameters: avian species of origin, organ of isolation and serotype.

The fimA gene of the avian strains, encoding the major subunit of the F1 pili, was also sequenced and analysed. The
APEC 17 and EC79 strains did not have the fimA gene, although they did have the fim $H$, indicating an incomplete fim operon. It is likely that in the absence of fimA the F1 fimbriae are not formed, explaining the lack of haemagglutination. The fact that a fim $A^{-}$strain, such as APEC 17, is virulent, does not exclude the possible role of type 1 pili in infection. In the virulence test used in this study, the bacteria were directly inoculated into the chicken body, where it has been shown that pili other than type 1 are activated ( $\mathrm{P}$ pili) and that $\mathrm{F} 1$ pili are repressed [17]. Type 1 pili are mainly expressed in the respiratory tract, which was completely bypassed in the virulence test used. Another test, using a more natural way of infection, would be necessary to investigate whether the $\operatorname{fimA}^{-}$strain remains virulent.

Marc and Dho-Moulin [13] sequenced the fimA gene from avian pathogenic E. coli and compared it with other available sequences (fimA from a uropathogenic strain, two avian strains and two Klebsiella pneumoniae strains). Upon comparison, four regions with considerable variation were found. Our fimA analysis of a larger collection of APEC strains confirmed the same four variable regions, but detected two additional variable domains (AA 8992 and 145-146). We were able to group the investigated strains into three groups (or families), based on the sequences of the variable domains. The grouping was consistent throughout the six domains, although the last two variable domains are identical for groups two and three. Our comparison also included the original sequenced fimA by Marc and Dho-Moulin [13] (GenBank accession number Z37500) and a fimA from E. coli of mammalian origin, from Peek et al. [15] (GenBank accession number AF206642). We also included a fimA sequence, amplified from an E. coli strain isolated from infected ostrich eggs. These strains were included to broaden the alignment to a wide variety of strains. We noticed that the E. coli strains of mammalian origin fell into one of the established 
groups and did not take an exclusive position. Even additional fimA sequences of mammalian origin from the study of Peek et al. [15] were incorporated into the multiple alignment: all of them fell within the proposed groups and the established variable domains (data not shown).

The grouping and the variable domains were independent of the serotype. Marc and Dho-Moulin [13] suggested that there could be an association between the variable domains and the $\mathrm{O} 2$ serotype. We found that the serotypes were distributed at random throughout the different groups and that consequently no association between serotype and fimA sequence could be found. Strains from the same serotype (e.g. the most frequent occurring O78 serotype) can be classified in different groups, with distinctly different FimA. The variable regions were also independent of the animal species of isolation (chicken, turkey, ostrich, peacock or mammalian origin), animal line (chickens layers, broilers or breeders), the organ of isolation (peritoneum, pericardium or trachea), the presence of the aerobactin receptor and the virulence for chicks.

These fimA variable domains allow the design of new, specific primers to detect the three fimA variants and to perform a more rapid classification of the F1 pili. Since there is one (conserved) adhesin, FimH, and three variants of the main FimA subunit, the nomenclature of $\mathrm{F}$ pili may be revised, allowing several classes of $\mathrm{F} 1$ pili. Hydrophilicity analysis of the FimA sequences shows that several variable domains harbour a hydrophilic nature. Notably region V2 and V3 are hydrophilic in all strains and, except in two strains, region 6 is also hydrophilic. These hydrophilic domains constitute potential epitopes at the surface of the pilus. This could allow an alternative approach to vaccine development based on partial fimA sequences (containing one or more variable domains).
In conclusion, this study elucidated the FimH and FimA molecular situation in E. coli from avian origin. Sequence analysis indicated the conserved nature of the FimH adhesin and the more variable nature of FimA. Future studies could investigate the adhesive properties of the different FimH variants to look for further correlations between protein sequences and specific phenotypes. Finally the molecular structure of FimA allows a non-serotype based grouping of $\mathrm{F}^{+}$APEC strains.

\section{ACKNOWLEDGEMENTS}

F. Vandemaele is supported by the IWT (Institute for the Promotion of Innovation by Science and Technology in Flanders) and the FWO (Fund for Scientific Research-Flanders). We also thank Carine Borgers for her skilled technical assistance.

\section{REFERENCES}

[1] Arné P., Marc D., Brée A., Schouler C., DhoMoulin M., Increased tracheal colonization in chickens without impairing pathogenic properties of avian pathogenic Escherichia coli MT78 with a FimH deletion, Avian Dis. 44 (2000) 343-355.

[2] Abraham S.N., Sun D., Dale J.B., Beachey E.H., Conservation of the D-mannoseadhesion protein among type 1 fimbriated members of the family Enterobacteriaceae, Nature 336 (1988) 682-684.

[3] Ausubel F.M., Brent R., Kingston R.E., Moore D.D., Seidman J.G., Smith J.A., Struhl, K., Short protocols in Molecular Biology, 2nd ed., Greene Publishing Associates and John Wiley \& Sons, NY, 1992.

[4] Dho-Moulin M., Fairbrother J.M., Avian Pathogenic Escherichia coli (APEC), Vet. Res. 30 (1999) 299-316.

[5] Dho-Moulin M., van den Bosch J.F., Girardeau J.P., Bree A., Barat T., Lafont J.P., Surface antigens from Escherichia coli $\mathrm{O} 2$ and $\mathrm{O} 78$ strains of avian origin, Infect. Immun. 58 (1990) 740-745.

[6] Dho M., Lafont J.P., Escherichia coli colonization of the trachea in poultry: comparison of virulent and avirulent strains in gnotoxenic chickens, Avian Dis. 26 (1982) 787-797. 
[7] Dho M., Lafont J.P., Adhesive properties and iron uptake ability in Escherichia coli lethal and nonlethal for chicks, Avian Dis. 28 (1984) 1016-1025.

[8] Gross W.G., Diseases due to Escherichia coli in poultry, in: Gyles C.L. (Ed.), Escherichia coli in domestic animals and humans, $\mathrm{CAB}$ International, Wallingford, UK, 1994, pp. 237-259.

[9] Klemm P., Jorgensen B.J., van Die I., de Ree H., Bergmans H., The fim genes responsible for synthesis of type 1 fimbriae in Escherichia coli, Mol. Gen. Genet. 199 (1985) 410-414.

[10] Krogfelt K.A., Bergmans H., Klemm P., Direct evidence that the FimH protein is the mannose-specific adhesin of Escherichia coli type 1 fimbriae, Infect. Immun. 58 (1990) 1995-1998.

[11] Krogfelt K.A., Klemm P., Investigation of minor components of Escherichia coli type 1 fimbriae: protein chemical and immunological aspects, Microb. Pathog. 4 (1988) 231238.

[12] Marc D., Arné P., Brée A., Dho-Moulin M., Colonization ability and pathogenic properties of a fim ${ }^{-}$mutant of an avian strain of Escherichia coli, Res. Microbiol. 149 (1998) 473-485.

[13] Marc D., Dho-Moulin M., Analysis of the fim cluster of an avian O2 strain of Escherichia coli: serogroup-specific sites within fimA and nucleotide sequence of fimI, J. Med. Microbiol. 44 (1996) 444-452.

[14] Mulvey M.A., Lopez-Boado Y.S., Wilson C.L., Roth R., Parks W.C., Heuser J., Hultgren S.J., Induction and evasion of host defenses by type-1 piliated uropathogenic Escherichia coli, Science 282 (1998) 14941497.

[15] Peek A.S., Souza V., Eguiarte L.E., Gaut B.S., The interaction of protein structure, selection and recombination on the evolution of the type-1 fimbrial major subunit (fimA) from Escherichia coli, J. Mol. Evol. 52 (2001) 193-204.

[16] Pouttu R., Puustinen T., Virkola R., Hacker J., Klemm P., Korhonen T.K., Amino acid residue Ala-62 in the FimH fimbrial adhesin is critical for the adhesiveness of meningitisassociated Escherichia coli to collagens, Mol. Microbiol. 31 (1999) 1747-1757.

[17] Pourbakhsh S.A., Dho-Moulin M., Bree A., Desautels C., Marineau-Doizé B., Fairbrother J.M., Localization of the in vivo expression of $\mathrm{P}$ and $\mathrm{F} 1$ fimbriae in chickens experimentally inoculated with pathogenic Escherichia coli, Microb. Pathog. 22 (1997) 331-341.

[18] Pourbakhsh S.A., Boulianne M., MarineauDoizé B., Fairbrother J.M., Virulence mechanisms of avian fimbriated Escherichia coli in experimentally inoculated chickens, Vet. Microbiol. 58 (1997) 195-213.

[19] Roggenkamp A., Neuberger H.R., Flugel A., Schmoll T., Heeseman J., Substitution of two histidine residues in YadA protein of Yersinia enterocolitica abrogates collagen binding, cell adherence and mouse virulence, Mol. Microbiol. 16 (1995) 1207-1219.

[20] Sokurenko E.V., Courtney H.S., Maslow J., Siitonen A., Hasty D.L. Quantitative differences in adhesiveness of type 1 fimbriated Escherichia coli due to structural differences in fimH genes, J. Bacteriol. 177 (1995) 3680-3686.

[21] Sokurenko E.V., Chesnokova V., Dykhuizen D.E., Ofek I., Wu X.R., Krogfelt K.A., Struve C., Schembri M.A., Hasty D.L., Pathogenic adaptation of Escherichia coli by natural variation of the FimH adhesin, Proc. Natl. Acad. Sci. USA 95 (1998) 8922-8926.

[22] Sokurenko E.V., Schembri M.A., Trintchina E., Kjaergaard K., Hasty D.L., Klemm P., Valency conversion in the type 1 fimbrial adhesin of Escherichia coli, Mol. Microbiol. 41 (2001) 675-686. 
